\title{
Apoptosis of Skeletal Muscle on Steroid-Induced Myopathy in Rats
}

\begin{abstract}
Recently apoptotic cell death has been reported in differentiated skeletal muscle, where apoptosis was generally assumed not to occur. To investigate whether apoptosis may contribute to the steroid-induced myopathy, rats treated with triamcinolone acetonide (TA) for 9 days were sacrificed for detecting apoptosis by in situ end labeling (ISEL) and electron microscopy in the soleus muscles. Immunohistochemical stainings of Fas antigen and p53 protein were performed to examine whether apoptosis-related proteins were present in the myopathy. Muscle fiber necrosis and apoptotic myonuclei appeared in the soleus muscles following administration of TA, while control muscles showed no evidences for apoptosis. Fas antigen was not detected in control muscles, but expressed in the soleus muscles of steroid-induced myopathy. Some of the Fas antigen-expressing muscle fibers were positive for ISEL. p53 protein was not detected in any muscle fibers. These findings indicate that TA can induce apoptosis in differentiated skeletal muscles, and Fas antigen might be partly related to apoptotic muscle death in steroid-induced myopathy.
\end{abstract}

Key Words : Myopathy, Steroid-Induced; Apoptosis; Fas Antigens, CD95; Protein p53; Muscular Diseases

\author{
Myung Ju Lee, Ji Shin Lee*, \\ Min Cheol Lee \\ Department of Plastic and Reconstructive Surgery, \\ College of Medicine, Chosun University, \\ Department of Pathology, College of Medicine, \\ Seonam University*, and Department of Pathology, \\ Chonnam National University Medical School and \\ Research Institute of Medical Sciences', Kwangju, \\ Korea
}

Received : 13 October 2000

Accepted : 23 April 2001

Address for correspondence

Min Cheol Lee, M.D.

Department of Pathology, Chonnam National University Medical School, 5 Hak-dong, Dong-ku, Kwangju 501-190, Korea

Tel : +82.62-220-4300, Fax : +82.62-227-3429

E-mail : mclee@chonnam.ac.kr

\section{INTRODUCTION}

Long-term administration of glucocorticoids in human and animals has been reported to induce steriod myopathy (1-3). Although any of the commonly available glucocorticoid preparations can cause myopathy, the fluorinated steroids, e.g., triamcinolone, betamethasone, and dexamethasone, seem more likely to produce muscle weakness. The typical findings of steroid myopathy are selective atrophy of type II muscle fibers and necrotic changes $(4,5)$. It has been suggested that glucocorticoid-induced mitochondrial damage can lead to muscle fiber necrosis $(4,6-8)$.

It is widely accepted that there are two major distinct modes of death in eukaryotic cells, i.e, necrosis and apoptosis (9-11). A poptosis in response to a variety of injurious stimuli has been demonstrated in several organs (12-16). In the lymphoid tissue and brain, glucocorticoids are known to easily induce apoptosis (17-19). Although differentiated skeletal muscles usually undergo necrotic death in response to injury, apoptotic cellular death occurs in dystrophin-deficient muscle $(20,21)$ and differentiated skeletal muscle after treatment with anabolic steroids (22).

Apoptosis is stimulated or inhibited by several mediator proteins. Fas antigen, which mediates apoptosis of lymphoid cells $(23,24)$, has been identified in diseased muscles (25-27). p53 protein was proven to stimulate apoptosis $(28,29)$.

This study investigated whether apoptosis might con- tribute to the death of differentiated skeletal muscle after administration of glucocorticoid. Two assays for the detection of apoptosis were employed, i.e, in situ end labeling (ISEL) and electron microscopic examinations $(30,31)$. Immunohistochemical stainings of Fas antigen and p53 protein were performed to examine the roles of these proteins in apoptosis of skeletal muscle in steroid-induced myopathy.

\section{MATERIALS AND METHODS}

Development of steroid-induced myopathy and tissue sampling

Twenty female Sprague-Dawley rats weighing between $180-210 \mathrm{~g}$ used in this study were maintained under standard condition. Rats were divided into two groups. Each group was given daily intraperitoneal injection of either physiologic saline $(n=5)$ or triamcinol one acetonide (TA) at a dose of $5 \mathrm{mg} / \mathrm{kg}$ body weight for 9 days $(n=15)$. Ten days after the completion of the injections, the soleus muscles from both legs were taken under ether anesthesia, and the weight was measured. A 5-10 mm thick cross section was taken from the midbelly of the right soleus, and mounted on cork in a manner such that the muscle fibers were perpendicular to the cork surface. The sections were quick- 
frozen in isopentane cooled by liquid nitrogen. The tissues were cut in $10 \mu \mathrm{m}$ thick serial sections in a cryostat maintained at $-20^{\circ} \mathrm{C}$ and mounted on probed microscopic slides (FisherBiotech, Pittsburgh, PA, U.S.A.). The frozen sections were used for histological studies, ISEL, and immunohistochemical studies. Remainder of the soleus muscles were used for electron microscopic examination.

In situ end labeling (ISEL)

A poptotic cells were visualized using the A popTag ${ }^{\circledR}$ Plus In Situ A poptosis Detection K it (Oncor, Gaithersburg, MD, U.S.A.). Briefly, frozen sections were fixed in $10 \%$ neutral buffered formalin for $10 \mathrm{~min}$ and postfixed in ethanol: acetic acid (2:1) for $5 \mathrm{~min}$ at $-20^{\circ} \mathrm{C}$. After washing in phosphatebuffered saline (PBS; $50 \mathrm{mM}$ sodium phosphate, pH 7.4, $200 \mathrm{mM} \mathrm{NaCl}$ ), sections were digested with proteinase K (20 $\mu \mathrm{g} / \mathrm{mL}$ in PBS; Sigma, St. Louis, MO, U.S.A.) for $15 \mathrm{~min}$ at room temperature and washed with distilled water. Slides were then put into $3 \% \mathrm{H}_{2} \mathrm{O}_{2}$ for 5 min to quench the endogenous peroxidase activity and washed with PBS. After adding the equilibration buffer for 1 min, terminal deoxynucl eotidyl transferase (TdT) enzyme was pipetted onto the sections, which were then incubated in a humidified chamber at $37^{\circ} \mathrm{C}$ for $1 \mathrm{hr}$. The reaction was stopped by putting sections in a stop/wash buffer. After washing, anti-digoxigenin-peroxidase was added to the slides. Slides were washed, stained with diaminobenzidine substrate, and counterstained with hematoxylin. A specimen known to be positive for apoptotic cells was used as a positive control for staining. Substitution of TdT with distilled water was used as a negative control. Positive muscle fibers were counted in all sections.

Immunohistochemistry for Fas antigen and p53 protein

Frozen sections were fixed with the ethanol/acetic acid fixative solution for $10 \mathrm{~min}$. The slides were immunostained with the avidin-biotin-peroxidase complex method (32). The endogenous peroxidase activity was blocked by incubating $1.5 \% \mathrm{H}_{2} \mathrm{O}_{2}$ in PBS. The slides were treated in the $10 \%$ normal in PBS for 30 min in order to block charged sites on tissue surfaces and then incubated with anti-Fas antigen (titer 1:50; clone UB-2; MBL, Watertown, MA, U.S.A.) or anti-p53 protein (titer 1:500; clone Ab-7; Oncogene, Cambrige, MA, U.S.A.) overnight at $4{ }^{\circ} \mathrm{C}$ The streptavidin-horseradish peroxidase (Research Genetics, H untsville, Alabama, U.S.A.) detection system was then applied. After treatment with $1 \%$ avidin-biotinylated horseradish peroxidase for $1 \mathrm{hr}$ at room temperature, the tissue sections were prepared for chromogen reaction with 3-amino-9-ethyl carbazole (Biomeda, Foster, CA, U.S.A.). The sections were counterstained with hematoxylin and mounted on Crys-
tal/M ount (Biomeda). Positive muscle fibers were counted in all sections.

\section{Electron microscopy}

The soleus muscles used for electron microscopy were initially kept in a slightly stretched state, via pins passed through their tendons into dental wax, while they were fixed for $1 \mathrm{hr}$ in $2.5 \%$ glutaral dehyde in $0.2 \mathrm{M}$ sodium cacodylate buffer, pH 7.2. Three pieces of muscle, measuring $2 \times 2 \times 3 \mathrm{~mm}$, were then excised and left for several hours in fresh fixative. They were then postfixed in 1\% osmiun tetroxide for $1 \mathrm{hr}$, dehydrated in graded alcohols, cleared in propylene oxide, and embedded in epoxy resin. Sections were cut $80 \mathrm{~nm}$ in thickness by an ultramicrotome, collected on uncoated grids, stained with uranyl acetate and lead citrate, and examined with a JEM 1200 EX II (JEOL).

\section{RESULTS}

Gross and histologic examinations of myopathy

Control rats gained weight during the experimental periods. In contrast, rats treated with TA showed loss of body weight (average weight loss, 26\%). The excised soleus muscle in TA-treated rats weighed $11 \%$ less than in control rats.

In light microscopic examinations, the muscle fibers of control rats were arranged in bundles or fascicles, surrounded by perimysial connective tissue. There was little variation in muscle fiber size or shape. Cytoplasmic staining was uniform, and small peripherally located nuclei were abundant (Fig. 1A). Variation in fiber size and shape was seen in the TA-treated soleus muscles. Atrophic fibers were noted occasionally (Fig. 1B). Some fibers had palestaining cytoplasm. N ecrotic fibers invaded by numerous macrophages were seen (Fig. 1C). A few small eosinophilic fibers with increased nuclei, indicative of atrophic change, were observed (Fig. 1D).

In situ end labeling (ISEL) and electron microscopy for apoptosis

No ISEL-positive signal was noted in the soleus muscles of control group (Fig. 2A). The TA-treated soleus muscles had 1 to 4 muscle fibers having apoptotic myonuclei (Fig. 2B). Myonuclei labeled with ISEL were found in muscle fibers, which had pale or intact staining cytoplasms (Fig. $2 \mathrm{C}$ and D). N ecrotic fibers were negative for ISEL (Fig. 2E and F).

In electron microscopic examinations, the nucle of control soleus muscles appeared just beneath the plasma mem- 


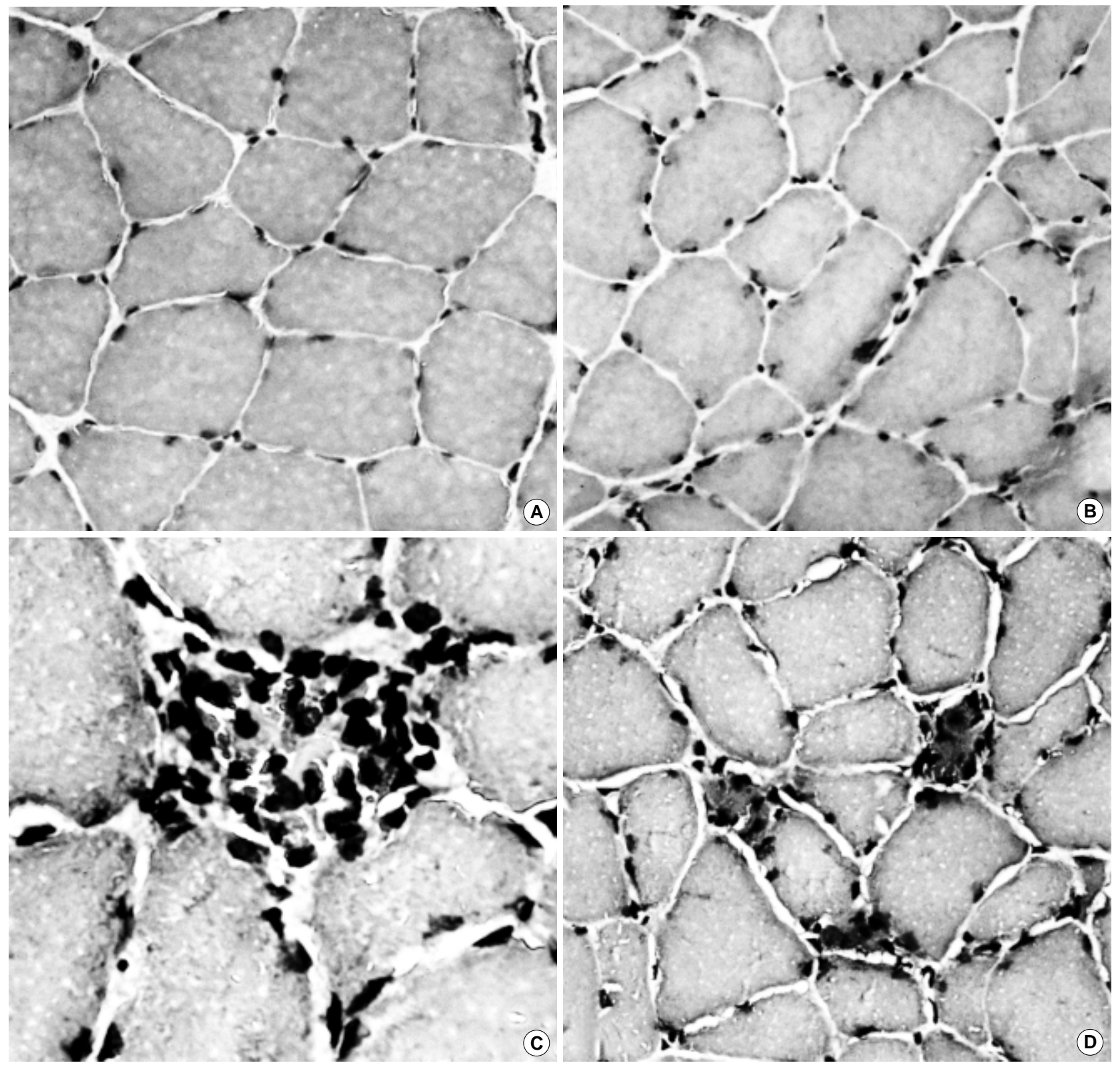

Fig. 1. Steroid myopathy on the soleus muscle $(H \& E)$. There is little variation in size or shape of muscle fibers in control group $(A, \times 200)$. Triamcinolone acetonide (TA)-treated soleus muscle reveals increased variation in size and shape and a few atrophic fibers $(B, \times 200)$, necrotic muscle fiber invaded by macrophages $(C, \times 400)$, and atrophic fibers with increased nucleation $(D, \times 200)$.

brane. They were elongated and ovoid in shape, with the chromatin distributed towards the periphery (Fig. 3A).

In the TA-treated soleus muscles, a few apoptotic myonucle characterized by irregularly condensed chromatin near the myonuclear membrane with intact sarcoplasm were noted (Fig. 3B). There were no discernible signs of degeneration or necrosis in fibers that contained apoptotic nuclei. Some muscle fibers contained swollen sarcoplasmic reticulum and mitochondria. N ecrotic muscle fibers, with focal loss of myofilaments and swollen nuclei containing dispersed chromatin, were al so observed.
Immunohistochemical staining of Fas antigen and p53 protein

Immunohistochemical staining of Fas antigen was not detected in the normal soleus muscles (Fig. 4A). Fas antigen was detected in the TA-treated soleus muscles and was mainly localized in the cytoplasm with granular pattern (Fig. 4B). N umber of Fas antigen-positive muscle fibers ranged from 1 to 8 per each muscle bundle. Some of theFas antigen-expressing muscle fibers were positive for ISEL (Fig. 4C and D). N ecrotic muscle fibers invaded by 


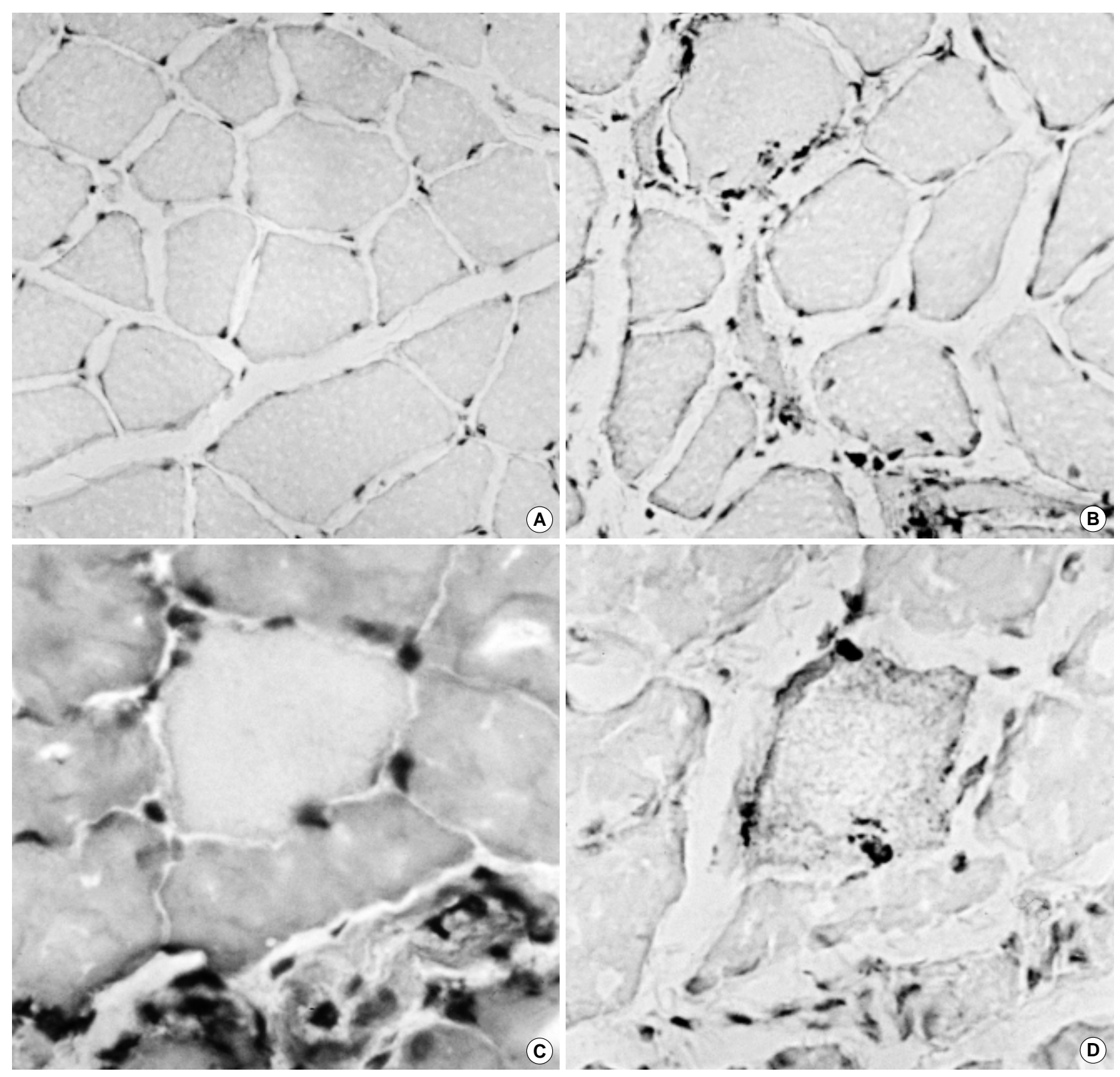

Fig. 2. In situ end labeling (ISEL) for apoptotic cells. None of myonuclei in control muscles show positive reaction $(A, \times 200)$. Positive staining in myonuclei of TA-treated soleus muscle is seen $(B, \times 200)$. Muscle fiber having pale cytoplasm $(C, \times 400)$ is positive by ISEL (D). (Fig. 2 continued next)

macrophages demonstrated no expression of Fas antigen. p53 protein was not detected in any muscle fibers of the normal or TA-treated soleus muscles.

\section{DISCUSSION}

Several of synthetic glucocorticoids have been developed and used in a wide range of medical and surgical fields. Despite their therapeutic benefits, the long-term administration of glucocorticoids in humans has often resulted in progressive muscle weakness and steroid myopathy. Characteristic biopsy findings from patients with steroid myopa thy are sel ective atrophy of type II muscle fibers and occa sional random fiber necrosis (1-3). As in human disease, steroid myopathy has been induced in a variety of experimental animals using a number of different steroids. The fluorinated steroids, e.g., triamcinolone, betamethasone, and dexamethasone, appear more likely to produce steroid myopathy $(4,5)$. N ecrotic lesions are easily induced in the rat soleus muscle by steroid administration (4). In this experiment, steroid-induced myopathies in rats were devel- 


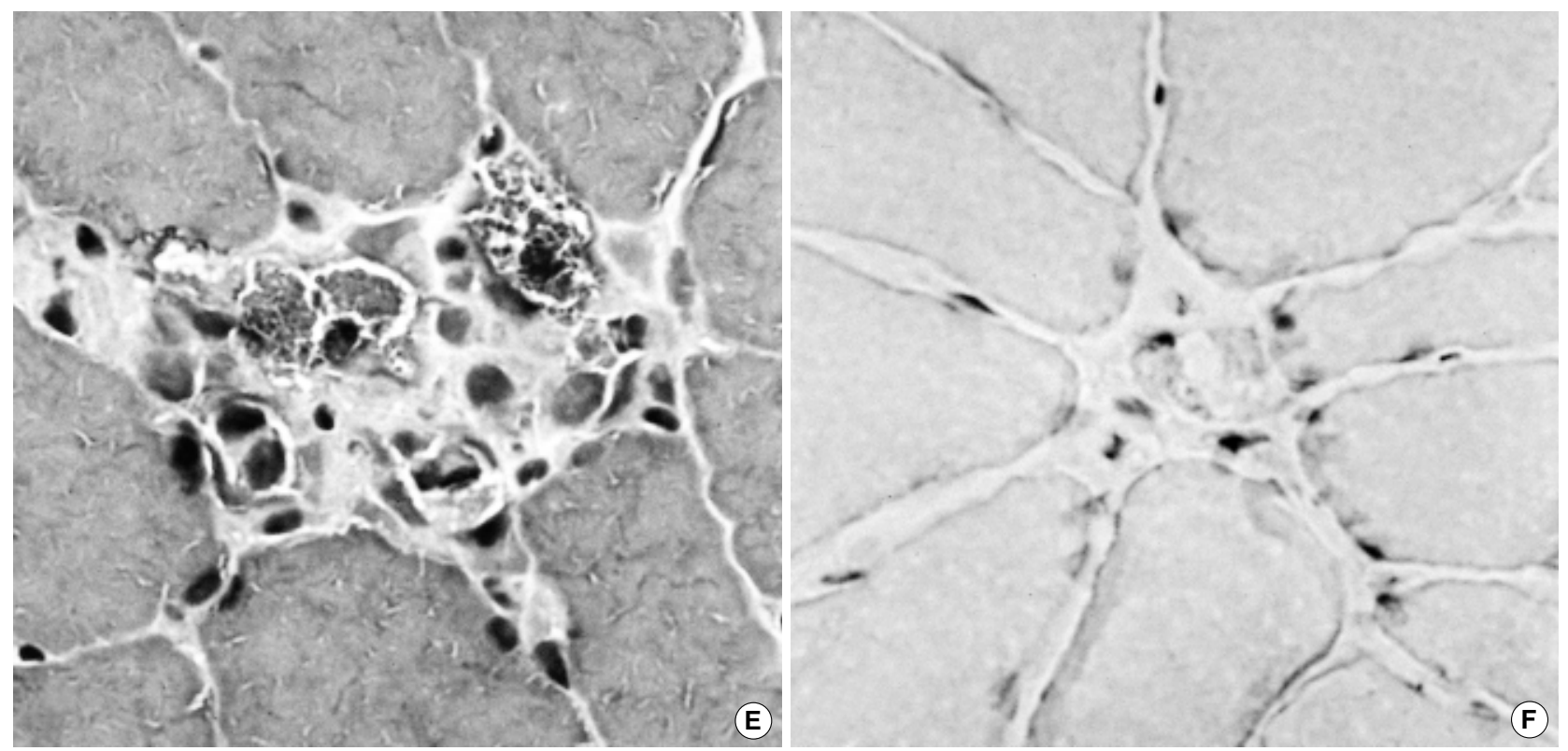

Fig. 2. (Continued from the previous page) In situ end labeling (ISEL) for apoptotic cells. Necrotic muscle fiber invaded by macrophages $(E, H \& E, \times 400)$ is negative for ISEL $(F)$.
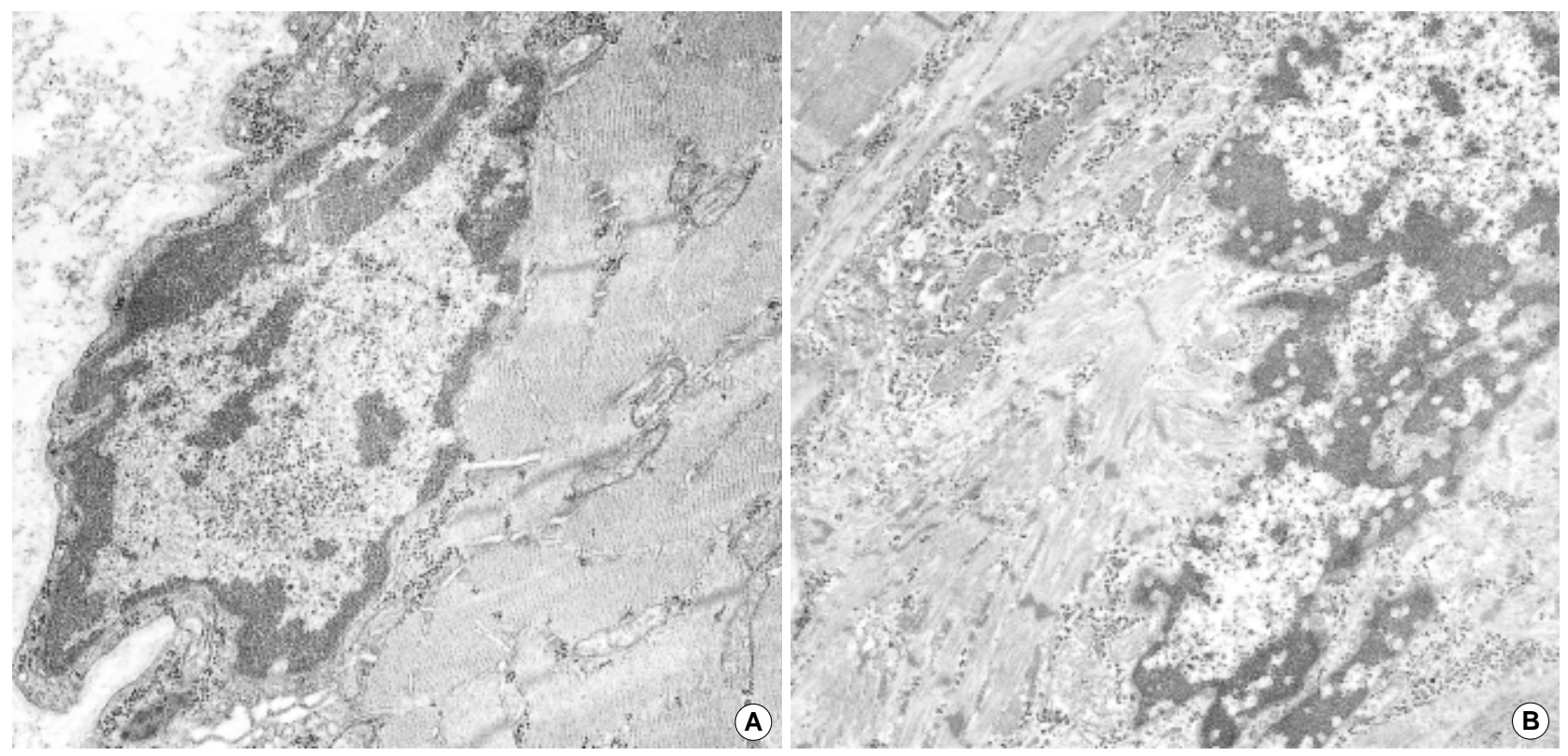

Fig. 3. Electron micrograph of a nucleus of the normal soleus muscle displays condensed chromatin along the nuclear membrane. Other organelles in the sarcoplasm appear normal $(A, \times 4,000)$. Apoptotic change in the TA-treated soleus muscle shows irregularly clumped chromatin of the nucleus without sarcoplasmic degeneration $(B, \times 10,000)$.

oped by daily intraperitoneal injections of TA for 9 days. In the steroid-induced myopathy, necrotic changes were found in frozen sections prepared for histological study and in electron microscopical examination. We thought that our experimental protocol (i.e. species, drug, duration) might be suitable for the study of this specific muscle lesion. Glucocortoid-induced mitochondrial damage leading to muscle fiber necrosis has been suggested in both ultrastructural and biochemical studies $(4,6-8)$. The sol eus muscle, which showed necrotic change in this experiment, consists mainly of type I fibers, being rich in mitochondrial oxidative enzymes (33).

A poptosis is a type of cell death that has been shown to differ from necrosis by defined ultrastructural and biochem- 


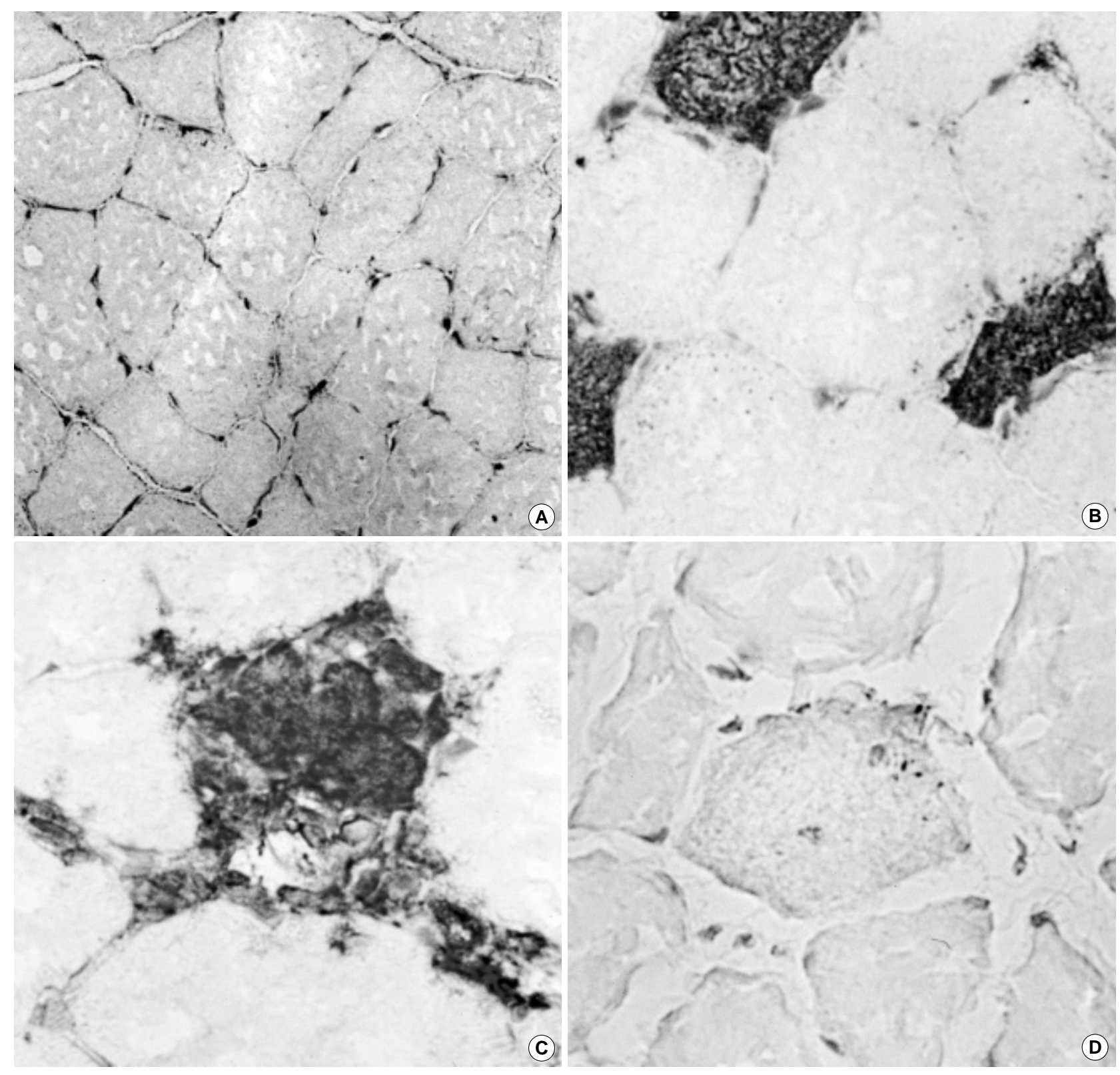

Fig. 4. Immunohistochemical staining of Fas antigen and ISEL. Fas antigen is not detected in control muscle (A, $\times 200)$, and is positive in the cytoplasm of the TA-treated soleus muscle $(B, \times 400)$. Fas antigen-positive muscle fiber $(C, \times 400)$ observed in the TA-treated soleus muscle is also positive by ISEL $(D, \times 400)$.

ical features (9-11). Through the implementation of ISEL and electron microscopy, we examined the possibility that apoptosis might contribute to the death of differentiated skeletal muscles of steroid myopathy. The technique of ISEL introduced by Gavrieli et al. (30) detects fragmented DN A via TdT reactions. This technique not only labels apoptotic cells al ready in progress but also potentially detects any cells where DN A strand breaks occurred without morphological changes. In addition, this technique can be performed on histologic sections so that both the quantification of apoptosis and the location of apoptotic nuclei can be determined. Morphological changes in cell structure representing apoptotic cell death can be identified by electron microscopy (31).

Glucocorticoids are known to easily induce apoptosis in some tissue. A poptosis of thymocytes (17) and theintestinal intraepithelial lymphocytes (18) has been experimentally induced by treatment with glucocorticoids. H assan et al. have al so demonstrated the exacerbation of apoptosis in the dentate gyrus of aged rats induced by dexamethasone (19).

Differentiated skeletal muscle cells of rats underwent apoptosis in response to glucocorticoid injury. Some myonu- 
clei were stained positively by ISEL. Peripheral condensation of nuclear chromatin, which appears at early stages of apoptosis and is distinct from necrotic cells, was observed by electron microscopy. Contrary to a widespread belief that differentiated skeletal muscle undergoes only necrotic death, apoptotic cellular death has been demonstrated in dystrophin-deficient muscle $(20,21)$ and differentiated skeletal muscle after treatment with anabolic steroids (22).

A poptosis in any particular cell lineage is mediated by exogenous influences, such as survival factors and the genes of the susceptible cell. One signal which leads to cell death by apoptosis is the Fas gene product $(23,24)$. The Fas molecule, synonymously referred to as APO-1, contains a cytoplasmic 'death domain' shared with the type I tumor necrosis factor receptor (34). To date, apoptosis induced by Fas antigen has been extensivley investigated in the lymphoid systems $(23,24)$. Immunohistochemical studies demonstrated that Fas antigen was expressed on muscle fibers from patients with various muscle wasting diseases, but not in normal muscle cells $(26,27)$. H owever, whether the muscle fiber that expressed the Fas antigen is involved in apoptotic processes has not been fully investigated. In this study, Fas antigen was expressed only in the TA-treated soleus muscles. Fas antigen was mainly detected in the cytoplasm of muscle fibers. Some Fas antigen-positive muscle fibers showed positive reaction for ISEL, indicating apoptosis. These findings suggest that Fas antigen expression might be related to apoptotic muscle death in steroid myopathy. The mechanism of the Fas antigen activation in the apoptotic process in steroid myopathy needs to be further investigated.

The role of tumor suppressor gene $p 53$ in the process of apoptosis induced by different stimuli has been studied. Specifically, radiation-induced apoptosis has been demonstrated to be strictly p53-dependent (29). H owever, glucocorticoid-triggered apoptosis in immature thymocytes was independent of p53 (35). We could not find the evidences for involvement of p53 protein in the apoptotic process in steroid myopathy.

In this study, the number of apoptotic myonuclei ranged from 1 to 4. Considering the facts that apoptosis is a rapid process and that ISEL method can only detect apoptotic nuclei for approximately 1 to $3 \mathrm{hr}$ following the onset of apoptosis (30), the small number of apoptotic nucle in this study is not an indicator of insignificance of apoptosis in steroid myopathy. The apoptotic cell death in steroid myopathy is mediated by Fas antigen expression in this study.

\section{REFERENCES}

1. Khaleeli AA, Edwards RH, Gohil K, McPhail G, Rennie MJ, Round J, Ross EJ. Corticosteroid myopathy: a clinical and patho- logical study. Clin Endocrinol Oxf 1983; 18: 155-66.

2. Ruff RL, Weissmann J. Endocrine myopathies. Neurol Clin 1988; 6: 575-92.

3. Bielefeld P. Present status of cortisone myopathy. Rev Med Interne 1996; 17: 255-61.

4. Braunstein PW Jr, DeGirolami U. Experimental corticosteroid myopathy. Acta Neuropathol Berl 1981; 55: 167-72.

5. Kelly FJ, McGrath JA, Goldspink DF, Cullen MJ. A morphological/biochemical study on the actions of corticosteroids on rat skeletal muscle. Muscle Nerve 1986; 9: 1-10.

6. Vignos PJ Jr, Greene R. Oxidative respiration of skeletal muscle in experimental corticosteroid myopathy. J Lab Clin Med 1973; 81: 365-78.

7. Tice LW, Engel AG. The effects of glucocorticoids on red and white muscles in the rat. Am J Pathol 1967; 50: 311-33.

8. Koski CL, Rifenberick DH, Max SR. Oxidative metabolism of skeletal muscle in steroid myopathy. Arch Neurol 1974; 31: 407-10.

9. Wyllie AH, Kerr JF, Currie AR. Cell death: the significance of apoptosis. Int Rev Cytol 1980; 68: 251-306.

10. Searle J, Kerr JF, Bishop CJ. Necrosis and apoptosis: distinct modes of cell death with fundamentally different significance. Pathol Annu 1982; 17: 229-59.

11. Arends MJ, Wyllie AH. Apoptosis: mechanisms and roles in pathology. Int Rev Exp Pathol 1991; 32: 223-54.

12. Takano YS, Harmon BV, Kerr JF. Apoptosis induced by mild hyperthermia in human and murine tumor cell lines: a study using electron microscopy and DNA gel electrophoresis. J Pathol 1991; 163: 329-36.

13. Fukuda K, Kojiro M, Chiu JF. Demonstration of extensive chromatin cleavage in transplanted Morris hepatoma 7777 tissue: apoptosis or necrosis? Am J Pathol 1993; 142: 935-46.

14. Lennon SV, Martin SJ, Cotter TG. Dose-dependent induction of apoptosis in human tumor cell lines by widely diverting stimuli. Cell Proliferat 1991; 24: 203-14.

15. Reynolds ES, Kanz FM, Chieco P, Moslen MT. 1, 1-Dichloroethylene: an apoptotic hepatotoxin? Environ Health Persp 1984; 57: 313-20.

16. Tominaga T, Kure S, Narisawa K, Yoshimoto T. Endonuclease activation following focal ischemic injury in the rat brain. Brain Res 1993; 608: 21-6.

17. Cohen JJ, Duke RC. Glucocorticoid activation of a calcium-dependent endonuclease in thymocyte nuclei leads to cell death. $J$ Immunol 1984; 132: 38-42.

18. Murosaki S, Inagaki-Ohara K, Kusaka H, Ikeda H, Yoshikai Y. Apoptosis of intestinal intraepithelial lymphocytes induced by exogenous and endogenous glucocorticoids. Microbiol Immunol 1997; 41: 139-48.

19. Hassan AH, von-Rosenstiel P, Patchev VK, Holsboer F, Almeida OF. Exacerbation of apoptosis in the dentate gyrus of the aged rat by dexamethasone and the protective role of corticosterone. Exp Neurol 1996; 140: 43-52.

20. Tidball JG, Albrecht DE, Lokensgard BE, Spencer MJ. Apoptosis precedes necrosis of dystrophin-deficient muscle. J Cell Sci 1995; 108: 2197-204. 
21. Sandri M, Carraro U, Podhorska-Okolov M, Rizzi C, Arslan P, Monti D, Franceschi C. Apoptosis, DNA damage and ubiquitin expression in normal and mdx muscle fibers after exercise. FEBS Lett 1995; 373: 291-5.

22. Abu-Shakra S, Alhalabi MS, Nachtman FC, Schemidt RA, Brusilow WS. Anabolic steroids induce injury and apoptosis of differentiated skeletal muscle. J Neurosci Res 1997; 47: 186-97.

23. Yonehara S, Ishii A, Yonehara A. A cell-killing monoclonal antibody (anti-Fas) to a cell surface antigen co-downregulated with the receptor of tumor necrosis factor. J Exp Med 1989; 169: 1747-56.

24. Watanabe-Fukunaga R, Brannan CI, Copeland NG, Jenkins NA, Nagata S. Lymphoproliferation disorder in mice explained by death in Fas antigen that mediates apoptosis. Nature 1992; 356: 314-7.

25. Yamada H, Nakagawa M, Higuchi I, Ohkubo R, Osame M. Type II muscle fibers are stained by anti-Fas antibody. J Neurol Sci 1995; 134: $115-8$.

26. Sahashi K, Ibi T, Ling L. Immunostaining of anti-Fas IgG1 antibody in diseased human muscle. Rinsho Shinkeigaku 1995; 35: 764-9.

27. Behrens L, Bender A, Johnson MA, Hohlfeld R. Cytotoxic mechanisms in inflammatory myopathies co-expression of Fas and protective Bcl-2 in muscle fibers and inflammatory cells. Brain 1997; 120: 929-38.

28. Clarke AR, Purdie CA, Harrison DJ, Morris RG, Bird CC, Hooper
ML, Wyllie AH. Thymocyte apoptosis induced by p53-dependent and independent pathways. Nature 1993; 362: 849-52.

29. Merritt AJ, Potten CS, Kemp CJ, Hickman JA, Balmain A, Lane $\mathrm{DP}$, Hall PA. The role of spontaneous and radiation-induced apoptosis in the gastrointestinal tract of normal and p53-deficient mice. Cancer Res 1994; 54: 614-7.

30. Gavrieli Y, Sherman Y, Ben-Sasson SA. Identification of programmed cell death in situ via specific labeling of nuclear DNA fragmentation. J Cell Biol 1992; 119: 493-501.

31. Kerr JFR, Gobe G, Winterford C, Harmon B. Anatomical methods in cell deaths. Methods Cell Biol 1995; 46: 1-27.

32. Hsu SM, Raine L, Fanger H. Use of avidin-biotin-peroxidase complex $(A B C)$ in immunoperoxidase techniques: a comparison between $A B C$ and unlabeled antibody (PAP) procedures. $J$ Histochem Cytochem 1981; 29: 577-80.

33. Okata S, Nonaka I, Chou SM. Muscle fiber type differentiation and satellite cell population in normally grown and neonatally denervated muscles in the rat. Acta Neuropathol Berl 1984; 56: 90-8.

34. Nagata S, Golstein P. The Fas death factor. Science 1996; 267: 1449-56.

35. Lowe SW, Schmitt EM, Smith SW, Osborne BA, Jacks T. p53 is required for radiation-induced apoptosis in mouse thymocytes. Nature 1993; 362: 847-9. 